\title{
Building a Patient-Centered Medical Home: Obtaining the Patient's Voice
}

\author{
Anje Van Berckelaer, MD, MS, Danae DiRocco, MPH, Monica Ferguson, MD, \\ Paula Gray, MSN, NP-C, Noora Marcus, BA, and Susan Day, MD, MPH
}

Purpose: Many primary care practices are currently attempting to transform into patient-centered medical homes (PCMHs), but little is known about how patients view aspects of the PCMH or how they define patient-centeredness.

Methods: We conducted 3 focus groups with patients from urban academic internal medicine practices. We asked questions about patients' perceptions of what patient-centered care should be; care quality, teams and access; diabetes self-management; and community connections and services. We used a grounded theory approach to the analysis.

Results: The global themes that arose in our focus groups included the desire for timely, clear, and courteous communication; a practice that is structured to facilitate an ongoing relationship with a provider who knows the patient; and a relationship that allows the patient both to trust the provider's guidance and to engage more fully in his or her own care.

Conclusions: Our patients want a provider to know them personally and to take time to listen to their issues. They feel that they cannot access their providers in a timely fashion, find our automated phone systems frustrating, and want more time with their provider. Although the technological and structural implementation of the PCMH requires considerable effort and resources, we cannot neglect the relationships we have with our patients. Patients should be involved in this process of change to ensure we address their concerns and preserve the primary care relationships they value. ( $\mathrm{J}$ Am Board Fam Med 2012;25:192-198.)

Keywords: Focus Groups, Medical Home, Patient-Centered Care, Patient Satisfaction, Qualitative Research, Quality Improvement

The patient-centered medical home $(\mathrm{PCMH})$ seeks to address some of the widely recognized shortcomings of primary care delivery by facilitating partnerships among the patient, physician, and

This article was externally peer reviewed.

Submitted 11 October 2010; revised 3 December 2010; accepted 16 December 2010.

From the Robert Wood Johnson Foundation Clinical Scholars (AVB); the Department of Family Medicine and Community Health (AVB); the Leonard Davis Institute of Health Economics (AVB); and the Division of General Internal Medicine (DD, MF, PG, NM, SD), University of Pennsylvania, Philadelphia.

Funding: This study was supported by a grant from the Bach Fund, a trust for research, education, and clinical care at Penn Presbyterian Medical Center.

Conflict of interest: Ms. DiRocco and Gray and Drs. Day and Ferguson report being employed by the practices from which patients were recruited. Dr. Day is a director of the American Board of Family Medicine, Lexington, Kentucky.

Corresponding author: Anje Van Berckelaer, MD, MSHP, 1303A Blockley Hall, 423 Guardian Drive, Philadelphia, PA 19104 (E-mail anje@upenn.edu). health care team. ${ }^{1}$ Patient-centered care is a core principle of this model. Although specific definitions of patient-centered care have varied, they typically are based on the belief that patients and their families desire increased involvement in and enhanced access to care as well as improved communication with their provider., ${ }^{2,3}$

Efforts to transform primary care practices into a PCMH have largely focused on funding and infrastructure, with less attention paid to the impact of these changes on patient-centered care. ${ }^{4,5}$ The Picker Institute has delineated 8 dimensions of patient-centered care, which include respect for patient values and preferences, information and education, access, continuity, physical comfort, care coordination, emotional support, and involvement of family. ${ }^{6}$ Although several measures of patientcenteredness exist, they lack concurrent validity, suggesting that they do not all measure the same 
domain of care. ${ }^{7}$ Studies have identified attributes of practices that correlate with patient satisfaction, such as continuity of and ease of access to care, effective communication with the provider, office efficiency, and personal manner of provider and staff $^{8,9}$; some of these overlap with patient-centered care dimensions, but this information has not been evaluated in the context of providing patient-centered care, nor has it been used to guide implementation of the PCMH. ${ }^{10-12}$ Indeed, early evaluations of the PCMH show a decline in patient satisfaction with implementation of the model. ${ }^{13}$ Medical home proponents increasingly recognize that patients should be more involved in this transformative process. $^{12,14}$

At the time of this study, our practices were at the beginning of the PCMH transformation. Our objective was to obtain patient input regarding their understanding of both patient-centered care and specific components of the PCMH to aid in its implementation as part of a multipractice quality improvement effort involving 3 academic ambulatory practices.

\section{Methods}

In the autumn of 2009, we conducted 3 focus groups with patients from 3 urban academic internal medicine practices (see Table 1 for the demographic composition of the practices). All 3 practices are training sites for internal medicine residents. At the time of the focus groups, 2 practices were implementing changes in team-based

Table 1. Practice Demographics of General Internal Medicine Outpatient Primary Care

\begin{tabular}{lc}
\hline Visits per year (n) & 75,000 \\
Race (\%) & 58.3 \\
African American & 34 \\
White & 1 \\
Hispanic & 3 \\
Asian & 3.7 \\
Other & 61 \\
Women (\%) & 52.9 \\
Average age (years) & \\
Payer mix (\%) & 40 \\
Managed care & 37 \\
PPO/Blue Shield/commercial & 10 \\
Medicare & 13 \\
Medicaid and Medicaid managed care & \\
\hline
\end{tabular}

PPO, preferred provider organization. care based on the Wagner Chronic Care Model, ${ }^{15}$ one of which was participating in a regional Chronic Care Collaborative, a medical home demonstration project, and had National Committee for Quality Assurance (NCQA) recognition as a level 3 medical home. Both these practices also had been part of a modified open-access scheduling initiative. The 2 practices without NCQA status were beginning to explore what becoming a medical home would mean to their patients. The unifying questions about patient-centeredness were asked of all 3 groups. Because different aspects of the medical home would not be experienced to the same extent by an unselected population, we stratified the groups to explore these aspects. Based on shared components of the chronic care model and PCMH, we explored care quality, teams, and access; diabetes self-management; and community connections and services.

We used a stratified purposive sampling strategy to identify patients for each group. For the quality of care group, we specified a minimum duration and number of visits in the practice to ensure sufficient recent exposure to the practice. For the diabetes group, we further specified a diabetes diagnosis for more than 1 year to ensure sufficient exposure to diabetes-specific programs such as nurse teaching visits. The specific community group criterion included residence for at least 3 years in the practices' principal primary care catchment area to assure knowledge of the community. Physicians from each practice provided lists of eligible patients (defined in Table 2); these patients were contacted by phone and invited to participate. In addition, recruitment flyers were posted at all 3 sites. The week preceding the focus groups, a research coordinator recruited additional participants from the practice waiting rooms. Research coordinators attempted to recruit an equal number of participants for each group and ensure uniform representation of each sex across groups.

Scripts for the focus groups were based on core aspects of the PCMH and were developed in collaboration with clinician leaders from each practice. We asked each group to define what patient-centered care meant to them. In addition, we asked the quality of care group about their experiences with different primary care clinician categories (nurse practitioner, attending physician, resident); their preferences for communication with the practice and their providers; and the role they would like to 
Table 2. Eligibility criteria

\begin{tabular}{ll}
\hline Group & \\
\hline Quality of care, teams, and access & $\bullet$ Patient at practice for at least 1 year \\
Diabetes self-management & $\bullet$ Visited the practice at least twice in the preceding year \\
& $\bullet$ Has had diabetes for $>1$ year \\
Community connections and services & $\bullet$ Patient at practice for $>6$ months \\
& $\bullet$ Resided in 1 of 4 zip codes surrounding the practices for $\geq 3$ years \\
\hline
\end{tabular}

play in their care. We asked the diabetes group about preferences for the composition of their primary care team and their opinion of group visits and self-management strategies. Finally, we asked the community group about their preference for their practice's involvement in the surrounding community.

The focus groups were led by an experienced professional facilitator who was not affiliated with the practices. Participants provided informed consent and received a $\$ 25$ gift card for their participation. This study was granted exemption from institutional review by the institutional review board of the University of Pennsylvania.

\section{Analysis}

Audio recordings were professionally transcribed using a computerized transcription program and were reviewed for accuracy. Two of the investigators (DD, NM) independently coded the transcripts, identifying broad categories of codes using an emergent coding method. Consensus among all authors was reached for broad code categories before coders returned to the transcripts to apply the general codes and identify more refined subcodes. Consensus was then reached for subcodes; coders independently applied these subcodes to the transcripts. Discrepancies in this coding round were again resolved by consensus among all authors. For this analysis, we examined the content of the text within and across codes to identify core themes relevant to participants' perceptions of the practices. We selected illustrative quotes to highlight central themes.

\section{Results}

The care team and access focus group had 5 participants, whereas the other 2 groups each had 6 participants. Patients from least 2 practices participated in each group. African-Americans, women, and older adults are slightly overrepresented compared with the practices included in the study. Table 3 describes the composition of each focus group.

The 3 broad codes identified to varying degrees in all focus groups were communication, structure of the practice and health system, and responsibility for or ownership of care. We used these categories as a framework to organize our thematic results. A global theme unifying these categories is the value of trust and the interpersonal aspects of the patient-clinician relationship. We discuss each code below through the use of illustrative quotations.

\section{Communication}

The themes related to communication can be broadly summarized as a desire for clear, timely, and courteous communication. A majority of these comments fit into a subcategory we called relation-

Table 3. Participant Characteristics

\begin{tabular}{|c|c|c|c|c|c|c|}
\hline \multirow[b]{2}{*}{ Group } & \multirow[b]{2}{*}{ No. } & \multirow{2}{*}{$\begin{array}{c}\text { Mean Age } \\
\text { (years) }\end{array}$} & \multirow{2}{*}{$\begin{array}{l}\text { Women } \\
\text { (n [\%] })\end{array}$} & \multicolumn{2}{|c|}{ Race (n [\%]) } & \multirow{2}{*}{$\begin{array}{l}\text { Mean Years at } \\
\text { Practice (n) }\end{array}$} \\
\hline & & & & African American & White & \\
\hline Care team and access & 5 & 66.8 & $4(80)$ & $4(80)$ & $1(20)$ & 15.8 \\
\hline Diabetes self-management & 6 & 59.3 & $5(83)$ & $5(83)$ & $1(17)$ & 23.6 \\
\hline Community connections and services & 6 & 61.3 & $4(66)$ & $3(50)$ & $3(50)$ & N/A* \\
\hline
\end{tabular}

*Only one participant in the focus group answered this question. 
al-they refer to relationships between patient, provider, other clinical staff, and community.

"You have to have a doctor who's ready to listen to you."

Respondents reported that being understood by the doctor was a central part of receiving patientcentered care. Being listened to by a provider with whom there was an established rapport arose with one of the highest frequencies.

"The notion cannot be that you're damn lucky to get through the door."

Courteous and respectful treatment by providers and staff was seen as a vital part of patient-centeredness. Many respondents had experienced unprofessional attitudes or insensitive behavior during office visits.

"The nurses, when they need to be taking care of business...they have a [personal] conversation...it's enough to drive you wild. That's not professional."

"Patient-centered care means...[the doctor] is working on what it is you're there for:... your reason for coming in."

Across focus groups, respondents identified patient involvement in setting the agenda for a visit as a mark of patient-centeredness. Some also indicated that nurse practitioners were more likely to let them set the agenda than physicians.

"I would like to get a lot more information than I am getting...especially about diet."

Participants also expressed a desire for particular content of the communication from the provider and the practice. Respondents wanted more detailed information about their care plan, either verbally or on paper, with lists of items to follow up. Specifically, they sought more information about diet, laboratory results, and medications.

"You wait an incessant period of time until you can talk to a buman being."

Finally, respondents commented on the process of communicating with the practice or provider. Many had difficulty getting through on the phone, and although calls are answered by nurses, patients would prefer to speak to their own physician. Respondents particularly disliked the automated phone system and wanted more reminders about appointments.

\section{Structure}

With respect to practice structure, respondents valued a system designed to facilitate provider continuity and contact. The majority of responses within the structure theme related to the practice structure. In both the quality of care and diabetes groups, participants were asked about team-based carethe inclusion of other providers (residents, nurse practitioners) in their care. Responses to this question varied depending on respondents' exposure to care teams.

"I think it's so confusing [to have a team of providers]. I want to see the same person."

Negative attitudes focused on issues of trust with the various providers, confusion and conflicting information, and the skill set of nonphysician team members.

“....I]t's good to have a team that can help you to get through some things that you wouldn't normally be able to get through."

The 2 practices providing team-based care offered chronic disease management to diabetics and patient self-management support partly by increasing the role of the nurse practitioner. Positive comments from the diabetic patients exposed to this model reflected the added support, proactive follow-up, and increased contact with the clinic.

"They have a diabetic team now... [The nurse practitioner] came in and introduced herself and said. . . 'we are bere to belp you between [visits] so you don't have to go to the emergency. You call us and we'll help you, whether you need to see your primary doctor, or belp you with your needles.'...I think that's really good."

Group visits were also seen as an opportunity to learn from and share with each other and as a way to increase motivation and encouragement.

"As diabetics, we need encouragement. We need to learn from each other."

"I think the nurse practitioners tend to listen a little better. They don't have their own agenda when you come in."

With respect to the composition of the care team, respondents appreciated being able to see a nurse practitioner for a visit sooner than they might see their doctor. In addition, nurse practitioners were seen as better listeners who spent more time with the patient. The pharmacist, although not affiliated with the practice, was seen as a valuable team member.

"It shouldn't be so burried ... I was here on time. It ain't my fault you got backed up... and then you want to burry me."

Respondents felt they did not have enough time with their providers; they found this particularly difficult when the doctor could not easily be 
reached outside the visit. In addition, the process for making follow-up appointments had recently changed at 2 of 3 practices to provide enhanced same-day and urgent access. Both the change and the new scheduling process were viewed as difficult.

"I wish that someone would explain to me about Medicare."

The complexity of the health care system and navigating insurance rules and paperwork was seen as a challenge. In particular, the diabetic group felt they needed help from staff with insurance issues. Others were also concerned about communication breakdowns between primary care provider, specialist, and pharmacist. Those patients who had experience with social workers found them helpful.

\section{Responsibility}

Finally, themes associated with "ownership" of or responsibility for care suggest a relationship and practice style that allows the patient both to trust the provider's guidance and to engage more fully in his or her own care.

"The role I'd like to take in my care is to be more active... I'd like to be more proactive in what I do to stay bealthy."

Participants expressed the desire to take an active role in their care and saw this as central to patient responsibility. Respondents appreciated taking part in treatment decisions and being offered treatment options, and they felt they needed to be prepared with questions.

"Doctors have so many patients, for you to get patient-centered care, you have to go into the doctor's office with a list of questions."

Participants felt that they should be engaged in their care by being generally informed about their health conditions.

Respondents had varying views about the provider's responsibility in primary care. Some saw the provider's role as ensuring that patients understand all aspects of their care and allowing patients to share in treatment decisions. A minority felt that the patient's role is to follow the doctor's instructions. Many felt that they had to be pushy to have their needs met.

"If you don't be kind of pushy...you fall through the cracks. You have to be aggressive and say what you need."

"I expect you to step outside the office, go on the scene... . There shouldn't be much distance between the service recipient and provider."
Lastly, a few respondents viewed the practice's responsibility as increasing outreach within their community. These patients felt that the practice should take the initiative and engage with community members to understand and address the community's health needs. Respondents felt that the practice should make information available about existing community resources, such as senior centers, health and wellness classes, and places to be physically active. This aligns well with the principle of care coordination extending to communitybased services outlined in the Joint Principles. ${ }^{1}$ Expectations within the community group were heterogeneous: some felt that a patient-centered practice should undertake outreach in the community, whereas others did not. However, patients did not distinguish between outreach from the university as a whole, the medical school, or the practice itself.

\section{Discussion \\ Key Findings}

Qualitative inquiry with patients as part of practice redesign offers valuable information without which our redesign would be unlikely to improve patient satisfaction. Indeed, because patient-centeredness by definition depends on respect for patient values and preferences, obtaining patient opinions is the only way to reliably reflect them in practice redesign.

In terms of content, the focus groups helped our practices better understand what patients seek in their medical homes and informed us what patients think when they hear terms such as "patient centered," "team-based care," and "shared decision making." The 3 organizing codes that emerged (communication, structure, and responsibility) align well with the pillars of the medical home (access and communication, team-based care, self management support, and care coordination). These are the basic tenets of primary care and need to be maintained as we restructure care.

The strong focus on trust and interpersonal aspects of the patient-practice and patient-clinician relationship supports greater inclusion of patients in the redesign process. Patients clearly want a clinician who knows them personally to take time to listen to their issues. Patient preference for a consistent provider is reflected in medical home principles, which emphasize continuity of care and 
a team headed by a single provider. Although teambased care has been proposed as an answer to the time constraints in primary care, participants raised important concerns about the need to maintain communication among team members to avoid paradoxically increased fragmentation of care. Those who had experienced team-based care as part of the chronic care demonstration project were reassuringly positive about this approach.

The focus groups also highlighted patients' desire for increased information about their health and how they should be caring for themselves, suggesting that patient-directed education must be part of self-management efforts. Although patients want to be active partners in their own care, they may resent the need to be their own advocates within the health care system. Similarly, they had mixed feelings about how involved they wanted their practice to be in their community; however, their expectation that the practice be familiar with community resources and the local environment was clear.

\section{Strengths and Limitations}

To our knowledge, this is the first qualitative assessment of patient opinions of specific aspects of the PCMH. As such, it offers a starting point for understanding the patient experience in primary care transformation.

Our focus groups were predominantly composed of minority women and broadly reflect the demographics of our practices, and the responses may be less applicable to other populations. In addition, small focus group size may have limited the breadth of discussion. Our findings may not apply to nonacademic practice settings in which community involvement and provider continuity likely play different roles. The study was not designed to allow practice-level comparisons or assess the early impact of the PCMH redesign in one practice on patient satisfaction. Because all 3 practices are located within 2 blocks of each other, serve a similar population of patients, and are part of the same practice organization, we believe the focus group feedback was relevant for all the practices.

We reached saturation on patient-centeredness questions, from which much of the discussion of practice structure and communication arose. Because the questions were asked of only one group each, the specific questions about diabetes selfmanagement and community involvement are less comprehensive. We included these questions to obtain a more complete view of the medical home with limited resources; however, a more comprehensive evaluation of patient views of the role of the medical home in the community and of patient self-management in chronic care are beyond the scope of this study. Further studies are needed to assess the degree to which the PCMH meets patient needs and expectations in other settings.

\section{Implications}

The discrepancy between the technological and structural aspects of the PCMH and the relational aspects of primary care may contribute to the decrease in satisfaction noted in PCMH demonstration projects. ${ }^{13}$ The NCQA standards commonly used for PCMH recognition, as other authors have noted, emphasize high-tech over high-touch aspects of the $\mathrm{PCMH}$ and primary care ${ }^{16}$; attempts to implement the PCMH solely according to these standards are likely to fail to meet patient expectations.

Adequate time with a consistent provider was an important component of patient-centeredness for our patients and reflects a core attribute correlated with patient satisfaction. ${ }^{9}$ Excessive emphasis on specific quality measures may make attention to other key patient-centeredness attributes such as a shared agenda and education difficult. ${ }^{4}$ Our patients valued the interpersonal aspects of their care based on a continuous relationship with their provider. This does not mean, however, that we must hold on to the traditional one-on-one doctor-patient structure of care. Patients who participated in group visits and team-based care with our nurse practitioners felt their experience was positive. This suggests that careful implementation of team-based care in our practices can preserve this relationship and enhance the patient experience for some chronically ill patients. Although our patients' preferences cannot be generalized to disparate practices, our findings suggest that practice redesign efforts may be enhanced by including a process to elicit patient opinion and preference.

\section{Conclusions}

The principal lesson from our patients was that the concerns that have fueled the national health care reform movement are indeed present in our practices. Patients feel that they cannot access their 
providers in a timely fashion, find our automated phone systems too complex, and want more time with a provider who knows them.

Our patients felt that they had to fight to get the information and attention they deserved. As we work to increase patient accountability in their decision making, we must recognize that patients still look to their providers for guidance. All patients need our assistance negotiating the complex world of health insurance, community resources, and care coordination. Team-based care and population management must ultimately improve care of individual patients. As the national dialogue searches for ways to fix the health care delivery system, it is crucial that we come back to our patients to make sure we address their concerns and include them in the process of change.

The authors gratefully acknowledge Barbara Boland, Mirar Bristol-Demeter, Robert Cato, Laurie Dean, Gillian Lautenbach, and Craig Wynne for their help in developing scripts and coordinating focus groups, and Fran Barg, Judy Shea, and David Grande for their comments on prior versions of this manuscript.

\section{References}

1. American Academy of Family Physicians, American Academy of Pediatrics, American College of Physicians, American Osteopathic Association. Joint Principles of the Patient-Centered Medical Home; 2007. Available at http://www.acponline.org/advocacy/where we_stand/medical_home/approve_jp.pdf. Accessed August 2, 2010.

2. Committee on Quality Health Care in America, Institute of Medicine. Crossing the quality chasm: a new health system for the 21 st century. Washington, DC: National Academy of Sciences; 2001.

3. Audet AM, Davis K, Schoenbaum SC. Adoption of patient-centered care practices by physicians: results from a national survey. Arch Intern Med. 2006;166:754-9.

4. Berenson RA, Hammons T, Gans DN, et al. A house is not a home: keeping patients at the center of practice redesign. Health Aff (Millwood). 2008;27: 1219-30.

5. Landon BE, Gill JM, Antonelli RC, Rich EC. Prospects for rebuilding primary care using the patientcentered medical home. Health Aff (Millwood). 2010;29(5):827-34.

6. Gerteis M, Edgman-Levitan S, Daley J, Delbanco T. Through the patient's eyes: understanding and promoting patient-centered care. San Francisco: JosseyBass; 1993.

7. Mead N, Bower P. Measuring patient-centeredness: a comparison of three observation-based instruments. Patient Educ Couns. 2000;39:71-80.

8. Anderson R, Barbara A, Feldman S. What patients want: a content analysis of key qualities that influence patient satisfaction. J Med Pract Manage. 2007; 22:255-61.

9. Otani K, Kurz RS, Harris LE. Managing primary care using patient satisfaction measures. J Healthc Manag. 2005;50:311-24, discussion 324-15.

10. Rittenhouse DR, Thom DH, Schmittdiel JA. Developing a policy-relevant research agenda for the patient-centered medical home: a focus on outcomes. J Gen Intern Med. 2010;25:593-600.

11. Carrier E, Gourevitch MN, Shah NR. Medical homes: challenges in translating theory into practice. Med Care. 2009;47:714-22.

12. Davis K, Schoenbaum SC, Audet AM. A 2020 vision of patient-centered primary care. J Gen Intern Med. 2005;20:953-7.

13. Nutting PA, Crabtree BF, Stewart EE, et al. Effect of facilitation on practice outcomes in the National Demonstration Project model of the patient-centered medical home. Ann Fam Med. 2010;8(Suppl 1):S33-44.

14. Homer CJ, Baron RJ. How to scale up primary care transformation: what we know and what we need to know? J Gen Intern Med. 2010;25:625-9.

15. Wagner EH, Austin BT, Von Korff M. Organizing care for patients with chronic illness. Milbank Q. 1996;74:511-44.

16. Ferrante JM, Balasubramanian BA, Hudson SV, Crabtree BF. Principles of the patient-centered medical home and preventive services delivery. Ann Fam Med. 2010;8:108-16. 